\title{
Room temperature tensile deformation behavior of a Ni-based superalloy with high $W$ content
}

\author{
De-long Shu, *Jun Xie, Feng-jiang Zhang, Gui-chen Hou, Zhen-jiang Wang, Shu-ling Xun, Jin-jiang Yu, \\ Xiao-feng Sun, Yi-zhou Zhou \\ Shi-changxu Innovation Center for Advanced Materials, Institute of Metal Research, Chinese Academy of Sciences, Shenyang 110016, China
}

\begin{abstract}
K416B Ni-based superalloy with high $\mathrm{W}$ content has good high temperature properties and low cost, which has a great development potential. To investigate the room temperature tensile property and the deformation feature of $\mathrm{K} 416 \mathrm{~B}$ superalloy, tensile testing at room temperature was carried out, and optical microscopy (OM), scanning electron microscopy (SEM) and transmission electron microscopy (TEM) were used to analyze the deformation and damage mechanisms. Results show that the main room temperature tensile deformation features of the K416B nickel-based superalloy are dislocations slipping in the matrix and shearing into $Y^{\prime}$ phase. The $<110>$ super-dislocations shearing into $Y^{\prime}$ phase can form the anti-phase boundary two coupled $(a / 2)<110>$ partial-dislocations or decompose into the configuration of two $(a / 3)<112>$ partial dislocations plus stacking fault. In the later stage of tensile testing, the slip-lines with different orientations are activated in the grain, causing the stress concentration in the regions of block carbide or the porosity, and cracks initiate and propagate along these regions.
\end{abstract}

Key words: Ni-based superalloy; high W content; microstructure; tensile behavior; deformation feature
CLC numbers: TG146.1 5
Document code: A
Article ID: 1672-6421(2021 03-192-07

\section{Introduction}

Due to their good oxidation resistance, high heatresistant capability and good mechanical properties, Ni-based superalloys have been widely used for preparing the parts of aero-engine, such as turbine guide-vane, turbine disks and other bearing parts ${ }^{[1-3]}$. The microstructure of the Ni-based superalloy mainly consists of $\gamma$ matrix, $\gamma^{\prime}$ phase and carbides ${ }^{[4-6]}$. To increase the solid solution strengthening level of the alloy, alloying elements with high melting points, such as $\mathrm{W}, \mathrm{Re}, \mathrm{Ru}$, and so on, are commonly added during composition designs ${ }^{[7]}$. However, the application of the nickel-based superalloys containing $\mathrm{Re}$ and $\mathrm{Ru}$ is limited, mainly due to the prices of these two elements being much more expensive than the others. The element $\mathrm{W}$, by contrast, has a lower price and could well improve the high temperature properties of the alloy ${ }^{[8,9]}$, which is thought to be an ideal alloying element to some extent to replace $\mathrm{Re}$ and $\mathrm{Ru}{ }^{[10]}$. W mainly distributes in $\gamma$ matrix

\footnotetext{
*Jun Xie
}

Male, born in 1986, Ph. D, Researcher. His research interests mainly focus on the pure melting for superalloy and the characterization for the properties of the superalloy.

E-mail: junxie@imr.ac.cn

Received: 2020-11-12; Accepted: 2021-02-24 and improves the mechanical properties of the alloy by solid solution strengthening ${ }^{[11]}$. Furthermore, the element $\mathrm{W}$ could reduce the coarsening rate of $\gamma^{\prime}$ phase during the alloy servicing at high temperature, due to its low diffusion coefficient ${ }^{[12]}$. It has been reported that the fatigue and stress rupture properties of a typical high $\mathrm{W}$ content polycrystalline superalloy $\mathrm{K} 416 \mathrm{~B}$, containing $16 \mathrm{wt} . \% \mathrm{~W}$, are comparable to those of a first-generation single crystal superalloy ${ }^{[13]}$. Therefore, the nickel-based superalloy with high $\mathrm{W}$ content has a great research value.

Some related research works ${ }^{[14,15]}$ show that the tensile properties of the Ni-based superalloy may be affected by the applied temperatures, which is closely related to the deformation mechanisms during tensile testing ${ }^{[16,17]}$. The deformation mechanisms of the alloy during tensile testing under different temperatures include dislocation loops formation, stacking fault (SF) and anti-phase boundary (APB)-coupled dislocation pairs formation, dislocation tangle formation, and finally, cross-slip and dislocation climb processes ${ }^{[18,19]}$. Although the deformation features of the Ni-based superalloy have been reported, but there are few reports on the tensile deformation behavior of the Ni-based superalloy with high $\mathrm{W}$ content at room temperature.

Because the properties of the K416B nickel-based superalloy with high $\mathrm{W}$ content at high temperature 
almost reaches the levels of the first-generation single crystal superalloy ${ }^{[13]}$, and the casting techniques of the polycrystalline alloys are much easier than the single crystal alloy, it is firmly believed that the $\mathrm{K} 416 \mathrm{~B}$ alloy has great advantages in use-cost, which means the alloy has a great potential for investigation and application. However, the research works on the nickel-based superalloy are mainly focused on the temperature-bearing capacities of the alloys, fewer on their properties at room temperature. For instance, the room temperature tensile behavior of the Ni-based superalloy with high $\mathrm{W}$ content is rarely investigated.

In this study, the tensile property of Ni-based superalloy with high $\mathrm{W}$ content was measured at room temperature. The microstructures of the alloy after tensile testing were observed by scanning electron microscopy (SEM) and transmission electron microscopy (TEM), and the tensile deformation mechanisms of the alloy were deeply investigated.

\section{Experimental procedure}

By means of $10 \mathrm{~kg}$ vacuum induction melting furnace, an ingot of Ni-based superalloy with high $\mathrm{W}$ content was prepared and cast into equiaxed crystal bars, and followed with refining at $1,600{ }^{\circ} \mathrm{C}$ for $5 \mathrm{~min}$ and pouring at $1,520^{\circ} \mathrm{C}$ and the cooling condition was air cooling. The nominal chemical composition of the alloy was given as follows (wt.\%): $0.13 \mathrm{C}-4.90 \mathrm{Cr}-$ 6.82Co-2.06Nb-5.75Al-16.0W-1.0Ti-1.0Hf-Ni. The alloy bars were processed into cylindrical specimens with a working gauge of $25 \mathrm{~mm}$ and a diameter of $5 \mathrm{~mm}$. The tensile testing was performed in an AG-25KNE model tensile testing machine at room temperature.

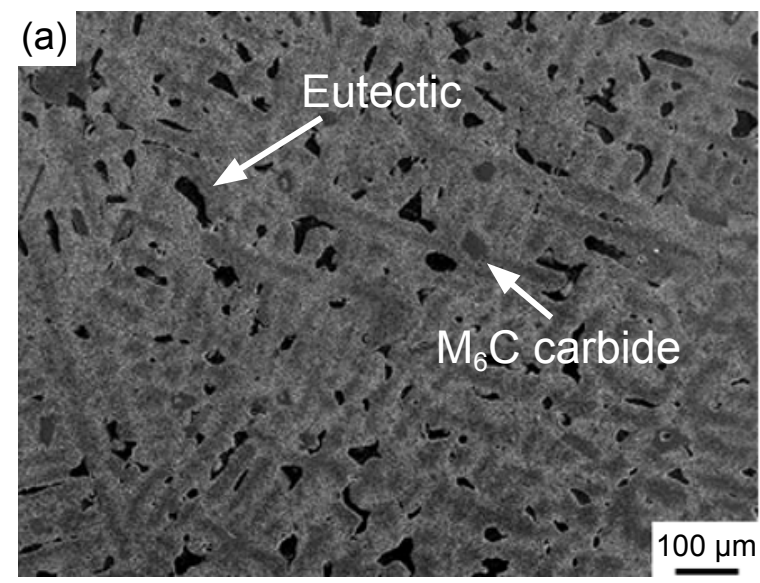

Fig. 1: SEM images of K416B Ni-based superalloy:
The alloy before or after the tensile testing was ground and polished, and then etched by the solution of $20 \mathrm{~mL} \mathrm{HCl}+5 \mathrm{~g}$ $\mathrm{CuSO}_{4}+25 \mathrm{~mL} \mathrm{H}_{2} \mathrm{O}$ in order to observe the microstructures under S-3400N SEM. The specimen after tensile testing was cut into a slice with the thickness of $0.5 \mathrm{~mm}$ from the regions near the fracture. After grinding and thinning down to $50 \mu \mathrm{m}$ mechanically, the TEM foils about $\Phi 3 \mathrm{~mm}$ were sectioned from the specimens and thinned by conventional twin jet polishing technique with the electrolyte consisting of $10 \%$ perchloric acid and $90 \%$ ethanol in volume fraction. By means of microstructure observation under TECNAI-20 TEM, the dislocation configuration and the deformation mechanisms of the alloy were investigated.

\section{Results}

\subsection{Microstructure of K416B Ni-based superalloy}

The microstructure of K416B Ni-based superalloy obversed by SEM is shown in Fig. 1. The morphology of dendrites in the alloy displays an irregular distribution feature, as shown in Fig. 1(a). The eutectics and $\mathrm{M}_{6} \mathrm{C}$ carbides with different sizes distribute in the inter-dendrite regions are marked by the arrow in Fig. 1(a). The morphology and size of $\gamma^{\prime}$ phase are different in the dendrite and inter-dendrite areas, as marked by the letters A and B in Fig. 1(b), respectively. The $\gamma^{\prime}$ particles with the size of $0.3-0.6 \mu \mathrm{m}$ dispersedly precipitate in the dendrite of the alloy, while those with the size of about 1-2 $\mu \mathrm{m}$ irregularly distribute in the inter-dendrite, as shown in Fig. 1(b).

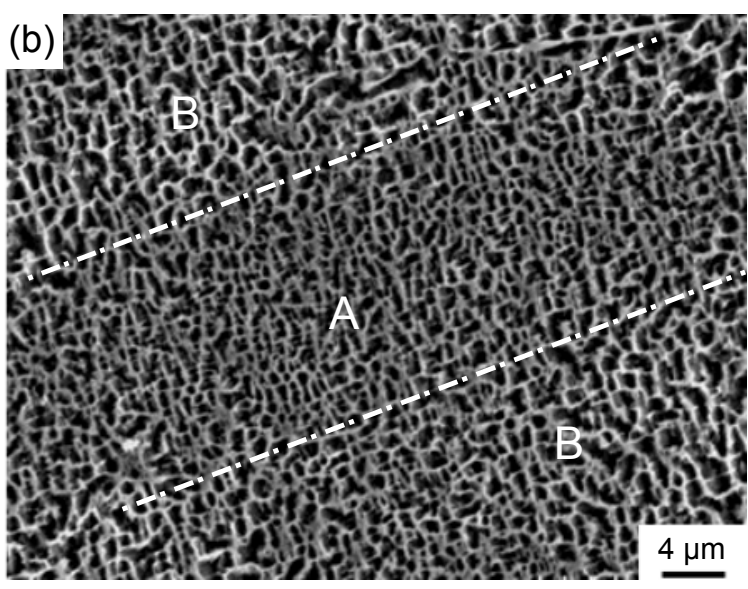

(a) dendrite morphology; (b) Y' phase morphology

\subsection{Tensile properties of K416B Ni-based superalloy}

The tensile properties of K416B Ni-based superalloy at room temperature are listed in Table 1. The average yield strength and tensile strength of the alloy are $749 \mathrm{MPa}$ and $975 \mathrm{MPa}$, and the corresponding elongation and reduction of area in the fracture alloy are measured to be $6 \%$ and $9 \%$, respectively.

\subsection{Tensile deformation feature of K416B Ni-based superalloy}

After room temperature tensile testing, the typical TEM microstructures of K416B Ni-based superalloy were observed, as shown in Fig. 2. The dislocation shearing $\gamma^{\prime}$ phase is marked by the white arrow in Fig. 2(a), and the dislocation bowing out in the matrix is marked by the black long arrow. The formation 
Table 1: Tensile properties of K416B Ni-based superalloy at room temperature

$\begin{array}{ccccc}\text { No. } & \begin{array}{c}\text { Yield strength } \\ (\mathrm{MPa})\end{array} & \begin{array}{c}\text { Tensile strength } \\ (\mathrm{MPa})\end{array} & \begin{array}{c}\text { Elongation } \\ (\%)\end{array} & \begin{array}{c}\text { Reduction of area } \\ (\%)\end{array} \\ \# 1 & 768 & 977 & 5.5 & 10 \\ \# 2 & 733 & 972 & 6 & 8 \\ \# 3 & 747 & 976 & 6.5 & 8\end{array}$
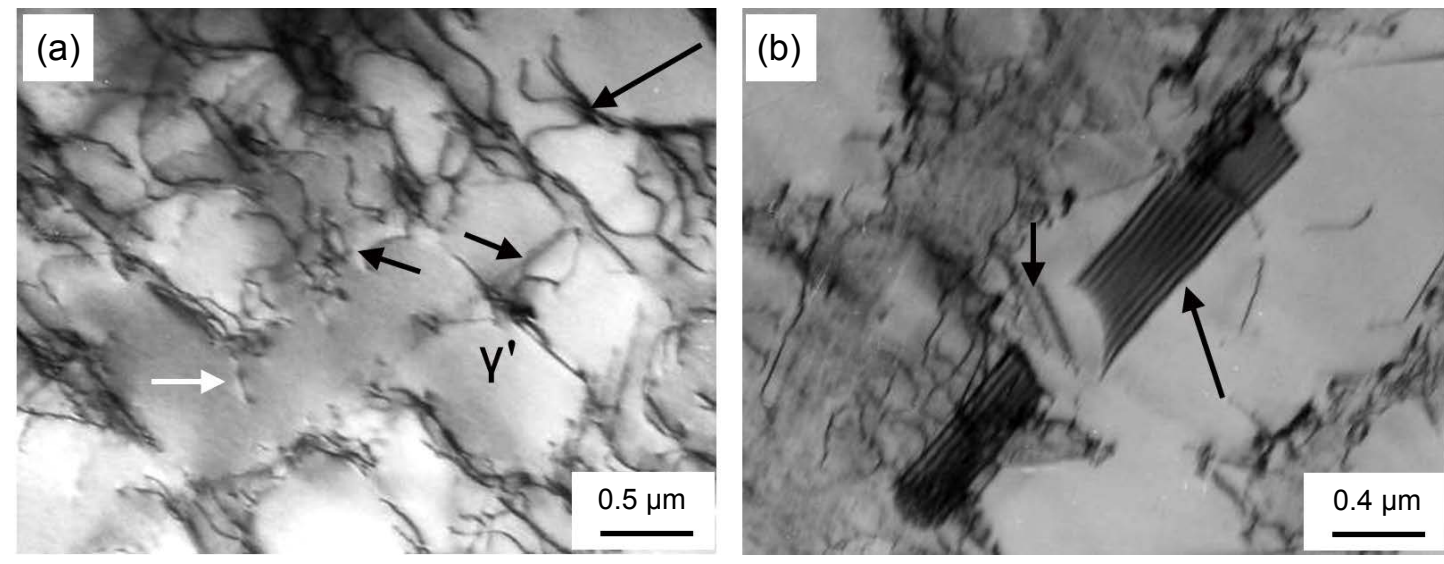

Fig. 2: TEM images of K416B superalloy after tensile fracture at room temperature: (a) dislocation bowing out and forming loops; (b) stacking fault

of dislocation-loops, marked by the black short arrows in Fig. 2(a), indicates that the moving dislocations bypass the $\gamma^{\prime}$ phase by Orowan mechanism. In another local region of the fracture alloy, some stacking faults and the anti-phase boundary (APB) plus a dislocation pair in the $\gamma^{\prime}$ phase were observed, respectively marked by the arrows in Fig. 2(b).

After tensile testing at room temperature, the dislocation configurations in the $\gamma^{\prime}$ phase with various diffraction contrasts are shown in Fig. 3, which are observed from different diffraction angles. The super-dislocations sheared into $\gamma^{\prime}$ phase are marked by 1, 2 and 3, respectively. When the diffraction vectors are $g_{020}, g_{\overline{1} \overline{1} 1}$ and $g_{20 \overline{2}}$, the Super-Dislocation 1 is out of contrast, as shown in Figs. 3(a), (d) and (f), respectively. According to the criterion of dislocation invisible $(g \cdot b=0)$, the Burgers vector of Dislocation 1 is identified as $b_{1}=\mathrm{a}$ [101], where "a" is the lattice constant of the $\gamma^{\prime}$ phase. The contrast of Dislocation 2 is invisible when the diffraction vectors are $g_{020}$ and $g_{1 \overline{1}}$, and the Burgers vector of Dislocation 2 could be calculated by $b_{2}=g_{020} \cdot g_{1 \overline{1} 1}=\mathrm{a}[10 \overline{1}]$. Dislocation 3 is out of contrast when the diffraction vector is $g_{1 \overline{1}}$, as shown in Fig. 3(c), indicating its Burgers vector is $b_{3}=\mathrm{a}[110]$. According to the analysis of the dislocation configuration above, it could be indicated that $a<110>$ super-dislocations can shear into the $\gamma^{\prime}$ phase and slip during tensile testing at room temperature.

The dislocation configuration of Schockley partial dislocations plus stacking fault (SF) in the $\gamma^{\prime}$ phase could be observed in Fig. 3, where the partials are marked by A and B, and the $\mathrm{SF}$ is marked by $\mathrm{C}$, respectively. When the diffraction vectors are $g_{020}, g_{\overline{1} \overline{1} 1}$ and $g_{20 \overline{2}}$, the partial Dislocation A is out of contrast, as shown in Figs. 3(a), (d) and (f). According to the criterion that partial dislocation is invisible in $\gamma^{\prime}$ phase when $b \cdot g= \pm(2 / 3)$ or $b \cdot g=0$, the Burgers vector of Schockley partial dislocation $\mathrm{A}$ is determined to be $b_{\mathrm{A}}=(\mathrm{a} / 3)[211]$. The contrast of partial Dislocation B is invisible when the diffraction vectors are $g_{020}, g_{31 \overline{1}}, g_{\overline{1} \overline{1} 1}$ and $g_{20 \overline{2}}$, as shown in Figs. 3(a), (b), (d) and (f), identifying the Burgers vector of Dislocation $B$ as $b_{B}=(a / 3)$ [11 2 ]. At the same time, the phase angles of stacking fault are indicated to be $\alpha=0$ or $2 n \pi$ when the diffraction vectors are $g_{31 \overline{1}}$ and $g_{3 \overline{1} 1}$, and the contrast of stacking fault is invisible, as shown in Figs. 3(b) and (e). The facts analyzed above indicate that the $<110>$ super-dislocation shearing into $\gamma^{\prime}$ phase can decompose into the configuration of two Schockley partial dislocations plus stacking fault. The decomposition reaction can be expressed as follows:

$$
\mathrm{a}[101] \rightarrow(\mathrm{a} / 3)[211]_{\mathrm{A}}+(\mathrm{SF})_{\mathrm{C}}+(\mathrm{a} / 3)[1 \overline{1} 2]_{\mathrm{B}}
$$

The partial dislocation pairs on both sides of APB in the $\gamma^{\prime}$ phase are marked by $D_{1}$ and $D_{2}$, respectively. When the diffraction vectors are $g_{020}, g_{\overline{1} \overline{1}}$ and $g_{20 \overline{2}}$, the dislocation pair $\mathrm{D}_{1}$ and $\mathrm{D}_{2}$ is out of contrast, as shown in Figs. 3(a), (d) and (f). According to the dislocation invisible criteria of $g \cdot b=0$, it can be identified that the Burgers vector of two partial dislocations is $b_{\mathrm{D} 1}=b_{\mathrm{D} 2}=g_{020} \cdot g_{\overline{1} \overline{1} 1}=g_{\overline{1} \overline{1} 1} \cdot g_{20 \overline{2}}=(\mathrm{a} / 2)[101]$. The decomposition reaction formula can be expressed as follows:

$$
\mathrm{a}[101] \rightarrow(\mathrm{a} / 2)[101]_{\mathrm{D} 1}+\mathrm{APB}+(\mathrm{a} / 2)[101]_{\mathrm{D} 2}
$$

After tensile fracture, the surface morphologies of the alloy are shown in Fig. 4, wherein, the slipping lines are activated along different directions in different grains. The end of the slipping traces at the porosity and the grain boundary may 

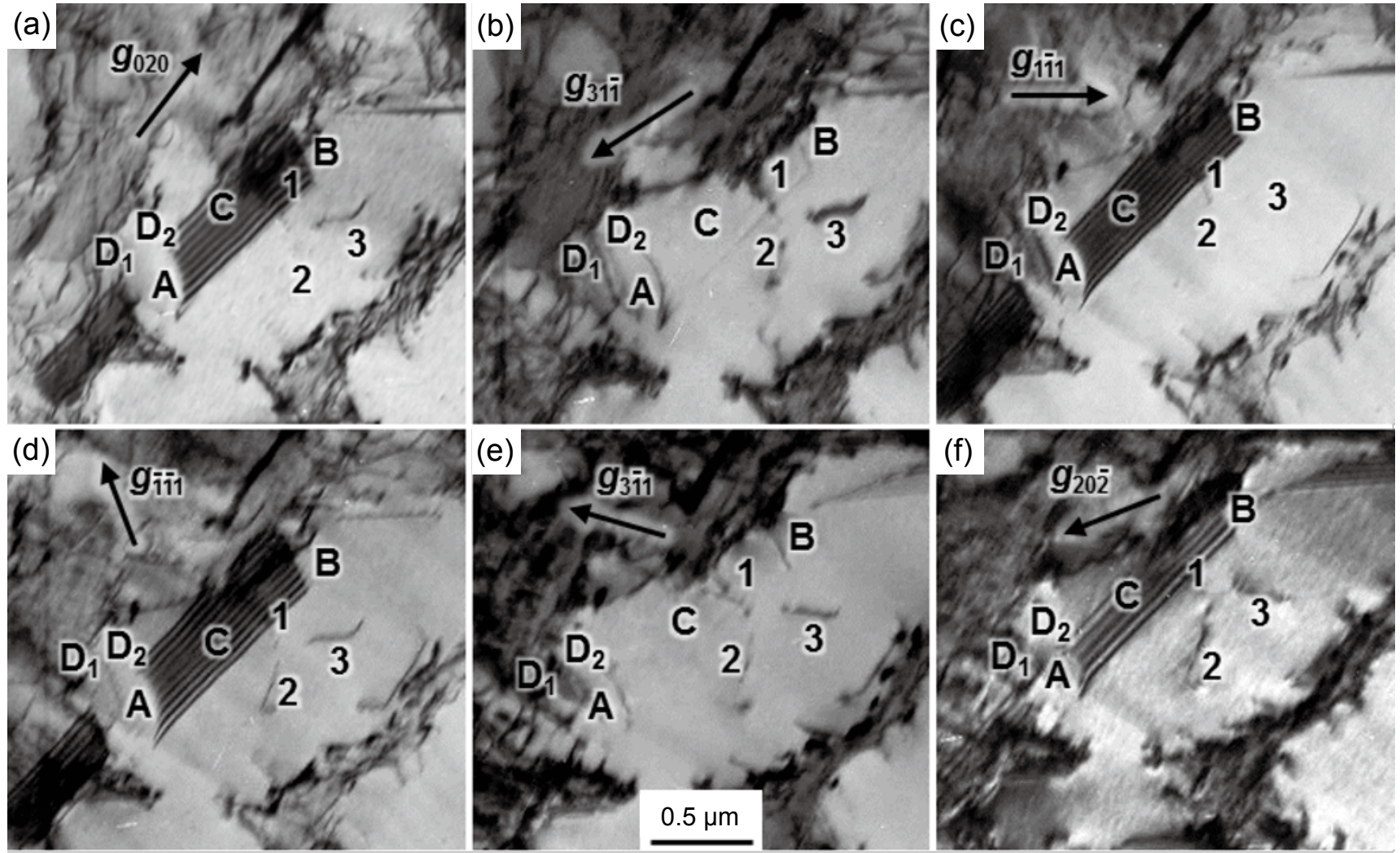

Fig. 3: Contrast analysis of dislocation configurations in Y' phase after tensile fracture: (a) $g_{020}$; (b) $g_{311}$; (c) $g_{111}$; (d) $g_{\overline{1} \overline{1} 1} ;(e) g_{3 \overline{1} 1} ;$ (f) $g_{20 \overline{2}}$

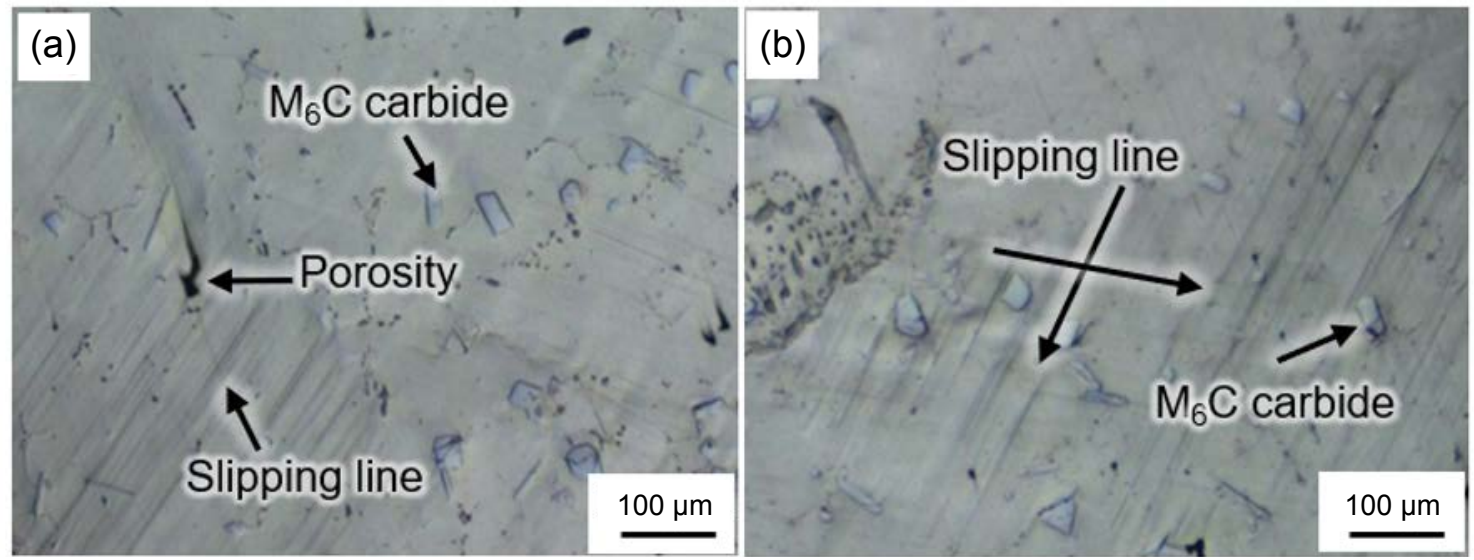

Fig. 4: OM images of alloy after tensile fracture: (a) slipping line ending at grain boundary; (b) slipping lines with different orientations in grain

cause the stress concentration, as shown in Fig. 4(a). In addition, when the slipping trace crosses over the block $\mathrm{M}_{6} \mathrm{C}$ carbide, the deformed stress will be accumulated in the region, which may promote the initiation of the micro-crack along the carbide interface, as shown in Fig. 4(b). Meanwhile, because the tensile testing is carried out at room temperature, and the experimental alloy has a high $\mathrm{W}$ content (about 16wt.\%), it can be indicated that the block $\mathrm{M}_{6} \mathrm{C}$ in the alloy is primary carbide precipitated after the alloy being poured, according to the Refs. [20, 21].

The SEM image in the vicinity of the fracture in the alloy after tensile fracture is shown in Fig. 5. The slipping lines

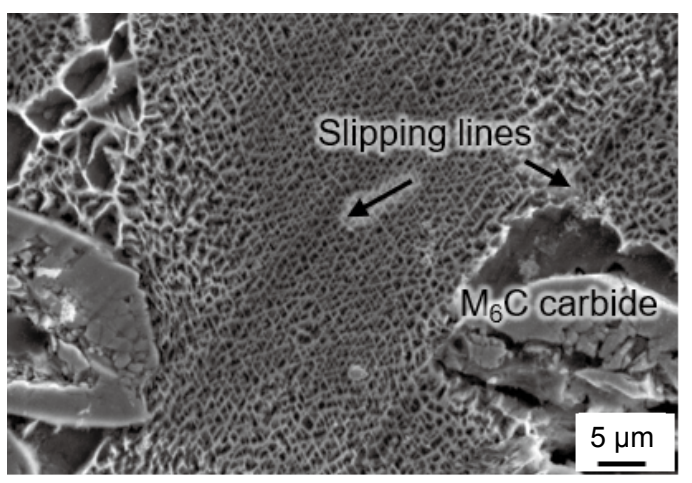

Fig. 5: SEM image of alloy after tensile fracture 
parallel to each other are indicated by the arrows. When the slipping lines cross over the block $\mathrm{M}_{6} \mathrm{C}$ carbide, the microcrack may easily initiate at the interface of $\mathrm{M}_{6} \mathrm{C}$ and $\gamma$ matrix, and the $\mathrm{M}_{6} \mathrm{C}$ carbide is more likely to be broken, as shown in the right of Fig. 5. This indicates that the block carbide is a weak region of the alloy during tensile testing at room temperature.

The fracture morphology of the alloy is presented in Fig. 6.
The macroscopic fracture is smooth, as shown in Fig. 6(a). In the local fracture, some porosity could be observed, which indicates that the tensile crack can also initiate from the porosity, as shown in Fig. 6(b). In another region, the block $\mathrm{M}_{6} \mathrm{C}$ carbide can be observed on the fracture, as shown in Fig. 6(c), where there are many slipping lines in the cleavage plane near the fragmented carbide, which coincides well with the results shown in Fig. 5.
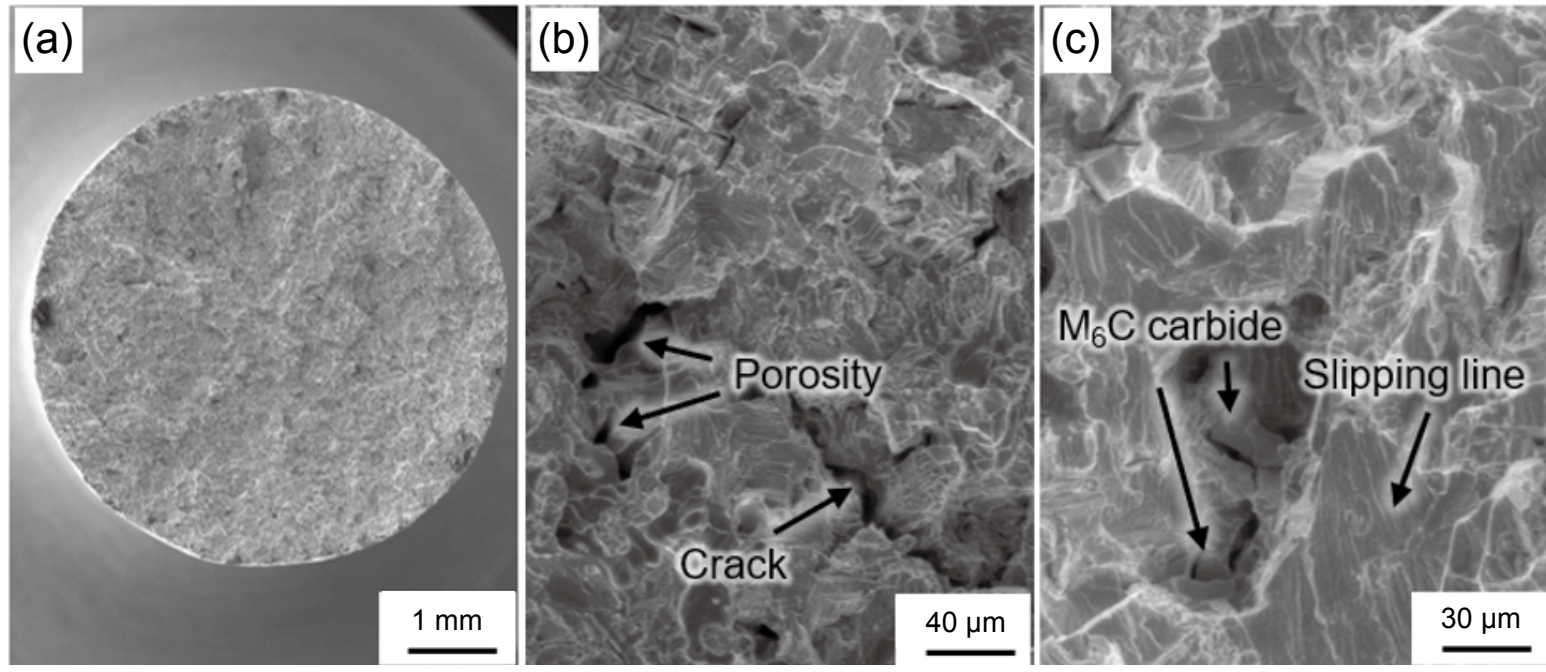

Fig. 6: Fracture images of alloy: (a) macroscopic morphology; (b) crack propagating in porosity; (c) slipping line ending at $\mathrm{M}_{6} \mathrm{C}$ carbide

\section{Discussion}

\subsection{Dislocation decomposition behavior during tensile at room temperature}

Due to the lattice misfit between $\gamma$ and $\gamma^{\prime}$ phase, dislocations slipping in the $\gamma$ matrix will pile up and cause the stress concentration at the interface of $\gamma / \gamma^{\prime}$ phase. To release the stress concentration, some dislocations may bypass the $\gamma^{\prime}$ phase by Orowan mechanism, as shown in Fig. 2(a), and some may shear into the $\gamma^{\prime}$ phase by different models, as shown in Fig. 2(b). According to the contrast analysis of dislocation configuration shown in Fig. 3, there are three models of the dislocations sheared into the $\gamma^{\prime}$ phase. One of them is a<110> dislocation decomposed into two $(\mathrm{a} / 3)<112>$ Schockley partial dislocations, marked by $\mathrm{A}$ and $\mathrm{B}$, plus $\mathrm{SF}$ on $\{111\}$ plane, as the letters A, B and C shown in Fig. 3. Another one is $a<110>$ dislocation decomposing into $(\mathrm{a} / 2)<110>$ partials plus $\mathrm{APB}$, as the letters $D_{1}$ and $D_{2}$ shown in Fig. 3. The third model is the shearing dislocation in $\gamma^{\prime}$ phase that keeps slipping without decomposing, as the numbers 1, 2 and 3 shown in Fig. 3. It could be indicated that the deformation mechanism of the alloy for tensile testing at room temperature is dislocation slipping in $\gamma$ matrix and shearing $\gamma^{\prime}$ phase.

Research shows that the dislocations decomposing in the $\gamma^{\prime}$ phase are mainly related to the APB energies and SF energies on various lattice planes ${ }^{[22]}$. At room temperature, the needed energy is calculated to be about $142 \mathrm{~mJ} \cdot \mathrm{mol}^{-1}$ for the shearing dislocations in the $\gamma^{\prime}$ phase to decompose into partials plus
APB on $\{111\}$ plane, while that on $\{001\}$ plane is about $28 \mathrm{~mJ} \cdot \mathrm{mol}^{-1}[23]$. However, the needed energy is only about $13 \mathrm{~mJ} \cdot \mathrm{mol}^{-1}$ for the dislocations to decompose into Shockley partial dislocations plus SF on $\{111\}$ plane. According to the calculation, it can be indicated that the sheared dislocations in the $\gamma^{\prime}$ phase are likely to decompose into partial superdislocations plus plane defects with lower energies, as shown by $D_{1}$ and $D_{2}$ in Fig. 3. The great instantaneous strain from the tensile testing is thought to be another main reason that the dislocation sheared into $\gamma^{\prime}$ phase could decompose into $(\mathrm{a} / 3)<112>$ partials plus $\mathrm{SF}^{[24]}$

The dislocation configuration of partials plus APB on $\{100\}$ plane is the dislocation structure with non-plane core, which can restrain the dislocations from slipping and cross-slipping ${ }^{[25]}$. Meanwhile, due to the great width of the SF, it is difficult for the Shockley super-dislocations at both ends of the SF to be constricted, which can increase the yield strength of the alloy.

According to the observation and analysis on the deformation feature, K416B superalloy displays a similar deformation mechanism during tensile testing at room temperature with other alloys containing lower $\mathrm{W}$ contents,

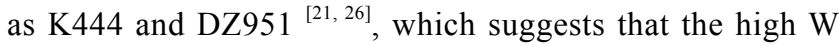
content has no obvious effect on the room temperature tensile deformation mechanism. However, the yield strength of $\mathrm{K} 416 \mathrm{~B}$ is higher than those of K444 and DZ951. This maybe due to that the higher $\mathrm{W}$ content in $\mathrm{K} 416 \mathrm{~B}$ can provide a greater solution strength level for $\gamma$ matrix, which improves the strength without reducing the elongation of the alloy. 


\subsection{Deformation and fracture feature of alloy during tensile testing at room temperature}

In the microstructure near the fracture of the alloy, significant slipping lines along two directions appear, as shown in Fig. 4 and Fig. 5. It can be observed that the crack initiation easily occurs when the slipping line crosses over the block $\mathrm{M}_{6} \mathrm{C}$. The deformation and fracture schematic diagrams of the alloy during tensile testing at room temperature are shown in Fig. 7.

During tensile testing, the main deformation mechanism is $\{111\}<110>$ slipping system activated ${ }^{[25]}$. Due to the crystal orientations of the grains in the alloys being varied, the effective stress for the slipping systems activated in each grain are different, as shown in Fig. 7(a). As tensile testing goes on, the increase of the effective stress can promote more slipping systems to be activated, which may cause the microstructure of the alloy to display slipping line morphologies, as shown in Fig. 5.

When significant slipping systems being activated simultaneously, because the $\mathrm{M}_{6} \mathrm{C}$ carbide is non-plastic and can hardly compatibly deform with $\gamma / \gamma^{\prime}$ phase, the stress concentration easily occurs at the interface of $\mathrm{M}_{6} \mathrm{C}$ and $\gamma$ matrix, which may cause the crack initiation, as shown in Fig. 7(b). Moreover, the crack initiation can also occur on the edge of various $\{111\}<110>$ primary/secondary slipping systems ${ }^{[27]}$, as indicated by the arrows shown in Fig. 7(b).

As tensile testing goes on, the crack tip can propagate rapidly along the normal stress orientation to cause the tensile fracture, and the fracture of the alloy may display a smooth feature, as shown in Fig. 7(c). It is well consistent with the observation results from Fig. 4 and Fig. 6.

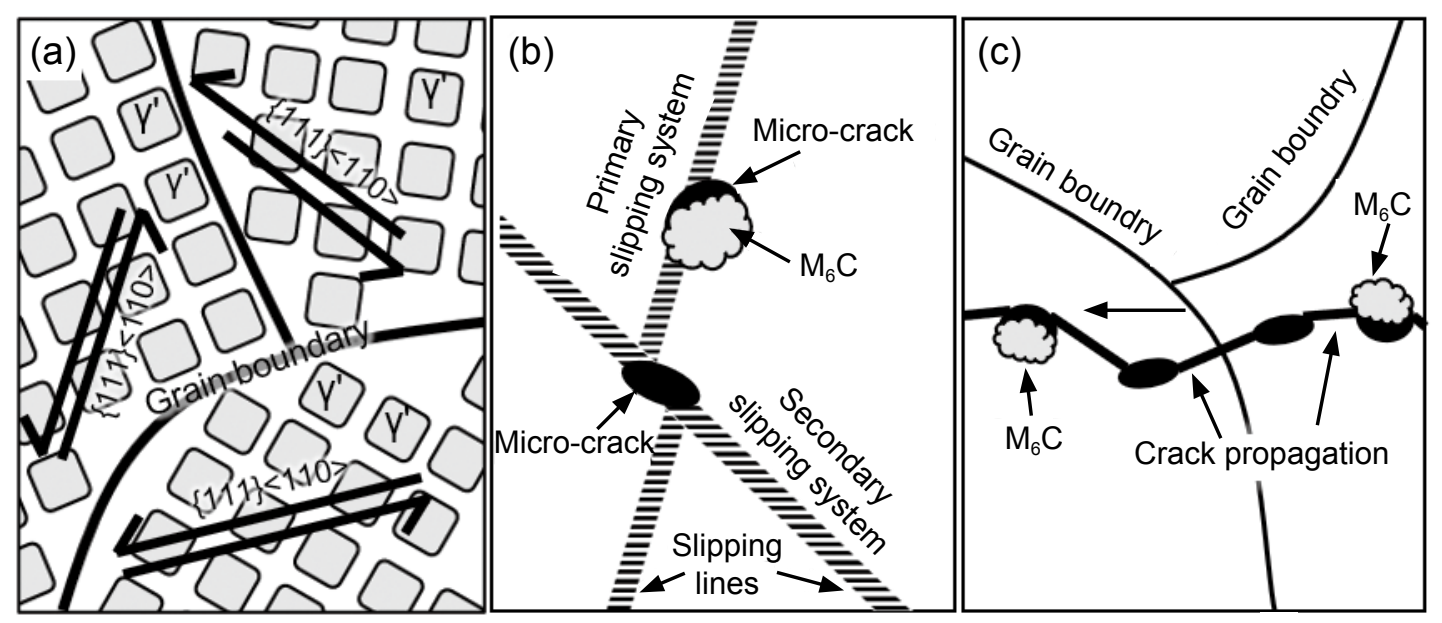

Fig. 7: Deformation and fracture schematic diagram of the alloy during tensile at room temperature: (a) slipping systems activation in various grains; (b) formation of slipping lines and micro-crack in a grain; (c) crack propagation and macrocrack formation

\section{Conclusions}

(1) During tensile testing at room temperature, the deformation mechanism of the alloy consists of the dislocation shearing into $\gamma^{\prime}$ phase, dislocation bowing, or forming loops by Orowan mechanism. The $<110>$ super-dislocations shearing into $\gamma^{\prime}$ phase may form the configuration of an antiphase boundary coupled $(\mathrm{a} / 2)<110>$ partial dislocation pair or decompose to form the stacking fault plus two $(a / 3)<112>$ partial dislocations.

(2) Different orientation slipping lines are activated in the matrix to cause the stress concentration in the regions of block $\mathrm{M}_{6} \mathrm{C}$ carbide or the porosity defect, and the crack can initiate and propagate along these regions during tensile testing, which is thought to be the fracture feature of the alloy.

\section{Acknowledgements}

This work was financially supported by the National Basic Research Program of China (Nos. 2010CB631200 and 2010CB631206), the National Natural Science Foundation of China (No. 51701212, No. 50931004, No. 51571196, No. 51601192 and No. 51671188), the State Key Laboratory of Solidification Processing in NWPU (SKLSP201747) and Liaoning Provincial Natural Science Foundation of China (No. 2019-MS-336), the Key Regional Project of Science and Technology Service Network Program, Chinese Academy of Sciences (No. KFJ-STS-QYZX-079), the Youth Innovation Promotion Association Project, Chinese Academy of Sciences (2020), and the National Science and Technology Major Project (J2019-VI-0018-0133).

\section{References}

[1] Kim I S, Choi B G, Hong H U, et al. Influence of thermal exposure on the microstructural evolution and mechanical properties of a wrought Ni-base superalloy. Materials Science and Engineering: A, 2014, 593: 55-63.

[2] Liu Y, Hu R, Li J S, et al. Hot working characteristic of as-cast and homogenized Ni-Cr-W superalloy. Materials Science and Engineering: A, 2009, 508(1): 141-147. 
[3] Qin X Z, Guo J T, Yuan C, et al. Thermal stability of primary carbides and carbonitrides in two cast $\mathrm{Ni}$-base superalloys. Materials Letters, 2008, 62(15): 2275-2278.

[4] Hou J S, Guo J T, Wu Y X, et al. Effect of hafnium on creep behavior of a corrosion resistant nickel base superalloy. Materials Science and Engineering: A, 2010, 527(6): 1548-1554.

[5] Sun W, Zhou L Z, Lou L H, et al. Thermal stability of primary $\mathrm{MC}$ carbide and its influence on the performance of cast $\mathrm{Ni}$ base superalloys. Materials and Design, 2015, 69: 81-88.

[6] Yang J X, Sun Y, Jin T, et al. Microstructure and mechanical properties of a Ni-based superalloy with refined grains. Acta Metallurgica Sinica, 2014, 50(7): 839-844. (In Chinese)

[7] Heckl A, Neumeier S, Goken M. The effect of Re and Ru on $\mathrm{y} / \mathrm{y}^{\prime}$ microstructure, $\mathrm{y}$-solid solution strengthening and creep strength in nickel-base superalloys. Materials Science and Engineering: A, 2011, 528(9): 3435-3444.

[8] Xie J, Yu J J, Sun X F, et al. Microstructure and creep behavior of $\mathrm{Hf}$-containing $\mathrm{K} 416 \mathrm{~B}$ as-cast $\mathrm{Ni}$-based superalloy with high W content. Chinese Journal of Nonferrous Metals, 2015, 25(6): 1490-1497. (In Chinese)

[9] Zhou T J, Ding H S, Ma X P, et al. Microstructure and stressrupture life of high $\mathrm{W}$-content cast $\mathrm{Ni}$-based superalloy after $1000-1100{ }^{\circ} \mathrm{C}$ thermal exposures, Materials Science and Engineering: A, 2018, 725: 299-308.

[10] Ritter N C, Sowa R, Schauer J C, et al. Effects of solid solution strengthening elements $\mathrm{Mo}, \mathrm{Re}, \mathrm{Ru}$, and $\mathrm{W}$ on transition temperatures in nickel-based superalloys with high $\gamma^{\prime}-$ volume fraction: Comparison of experiment and CALPHAD calculations. Metallurgical and Materials Transactions A, 2018, 49(8): 3206-3216.

[11] Yang $D Y$, Zhang $X$, Jin $T$, et al. Influence of cobalt, tungsten, and titanium on stress-rupture properties of nickel-base single crystal superalloy. Rare Metal Materials and Engineering, 2005, 34(8): 1295-1298.

[12] Sudbrack C K, Ziebell T D, Noebe R D, et al. Effects of a tungsten addition on the morphological evolution, spatial correlations and temporal evolution of a model $\mathrm{Ni}-\mathrm{Al}-\mathrm{Cr}$ superalloy. Acta Materialia, 2008, 56(3): 448-463.

[13] Xie J, Yu J J, Sun X F, et al. High-cycle fatigue behavior of K416B Ni-based casting superalloy at $700^{\circ} \mathrm{C}$. Acta Metallurgica Sinica, 2016, 52(3): 257-263. (In Chinese)

[14] Sajjadi S A, Nategh S, Isac M, et al. Tensile deformation mechanisms at different temperatures in the Ni-base superalloy GTD-111. Journal of Materials Processing Technology, 2004, 155-156: 1900-1904.
[15] Wang X G, Liu J L, Jin T, et al. Tensile behaviors and deformation mechanisms of a nickel-base single crystal superalloy at different temperatures. Materials Science and Engineering: A, 2014, 598: 154-161.

[16] Bai G H, Li J S, Hu R, et al. Effect of temperature on tensile behavior of Ni-Cr-W based superalloy. Materials Science and Engineering: A, 2011, 528(4): 1974-1978.

[17] Yang $G X, X u Y F$, Jiang $L$, et al. High temperature tensile properties and fracture behavior of cast nickel-base K445 superalloy. Progress in Natural Science: Materials International, 2011, 21(5): 418-425.

[18] Kumar A L, Chaitanya N B, Kumar B S, et al. Study of tensile fracture mechanisms of a Ni-base superalloy supercast 247A. Procedia Materials Science, 2014, 5: 1090-1096.

[19] Wang L, Wang S, Song X, et al. Effects of precipitated phases on the crack propagation behaviour of a Ni-based superalloy. International Journal of Fatigue, 2014, 62(SI): 210-216.

[20] Yang J X, Zheng Q, Sun X F, et al. Relative stability of carbides and their effects on the properties of K465 superalloy. Materials Science and Engineering: A, 2006, 429(1): 341-347.

[21] Zhang P, Yuan Y, Li B, et al. Tensile deformation behavior of a new Ni-base superalloy at room temperature. Materials Science and Engineering: A, 2016, 655: 152-159.

[22] Vitek V. Atomic structure of dislocations in intermetallics with close packed structures: A comparative study. Intermetallics, 1998, 6(7-8): 579-585.

[23] Foiles S M, Daw M S. Application of the embedded atom method to Ni3Al. Journal of Materials Research, 1987, 2(1): $5-15$.

[24] Tian N, Tian S G, Yan H J, et al. Deformation mechanisms and analysis of a single crystal nickel-based superalloy during tensile at room temperature. Materials Science and Engineering: A, 2019, 744: 154-162.

[25] Tian S G, Zeng Z, Liang F S, et al. Creep behavior of a 4.5\%Re single crystal nickel-based superalloy at intermediate temperatures. Materials Science and Engineering: A, 2012, 543: 104-109.

[26] Xia P C, Yu J J, Sun X F, et al. Influence of thermal exposure on $Y^{\prime}$ precipitation and tensile properties of DZ951 alloy. Materials Characterization, 2007, 58(7): 645-651.

[27] Zhou T J, Ding H S, Ma X P, et al. Effect of precipitates on high-temperature tensile strength of a high $\mathrm{W}$-content cast Ni-based superalloy. Journal of Alloys and Compounds, 2019, 797: 486-496. 